\title{
Performed Clinical Interpretation Toxicity Term Code
}

National Cancer Institute

\section{Source}

National Cancer Institute. Performed Clinical Interpretation Toxicity Term Code. NCI

Thesaurus. Code C93907.

A coded value specifying the deg ree to which a substance is able to damage an exposed organism. 